\title{
Blind Electronic Mail System
}

\author{
Maham Imtiaz ${ }^{1}$, Samina Khalid ${ }^{1}$, Saleema Khadam ${ }^{1}$, Sumaira Arshad ${ }^{1}$, Ali Raza $^{1}$, Tehmina Khalil ${ }^{2}$ \\ ${ }^{1}$ Department of Computer Science and Information Technology, Mirpur University of Science and Technology, \\ Pakistan \\ ${ }^{2}$ Department of Software Engineering, Mirpur University of Science and Technology, Pakistan \\ Correspondence: Samina Khalid, Department of Computer Science and Information Technology, Mirpur \\ University of Science and Technology, Pakistan.
}

Received: December 14, 2020

Accepted: January 4, 2021

Online Published: January 8, 2021

doi:10.5539/cis.v14n1p14

URL: https://doi.org/10.5539/cis.v14n1p14

\begin{abstract}
Web has gotten one of the essential civilities for everyday living. Each individual is generally getting to the information specially E-mail and data through Web. Nonetheless, daze individuals face challenges in getting to these content materials, likewise in utilizing any help given through Web. The progression in PC based available frameworks has opened up numerous roads for the outwardly debilitated over the globe in a wide manner. Sound input based virtual climate like, the screen readers have helped Blind individuals to get to Web applications colossally. We depict the Voice-mail framework design that can be utilized by a Blind individual to get to messages effectively and productively. The commitment built by this examination has empowered the visually impaired public to deliver and get voice-based e-mail messages in their local language with the assistance of a PC (Ingle, P., Kanade, H., \& Lanke, A. 2016).
\end{abstract}

Keywords: text-to-speech, speech-to-text conversion, web speech API

\section{Introduction}

Internet is the basic mean of communication now a days so, the first thing that comes into our mind is the communication through e-mail by being connected to the network. The main criteria to access e-mail is that we must be able to see if it is not visible then it is useless, but there are some special people around the world who are deprived of this ability. This makes the Internet useless for visually impaired. Even the systems that are available with speech to text (STT), text to speech (TTS) and screen readers do not provide full efficiency to the blind people (Ingle, P., Kanade, H., \& Lanke, A. 2016), (Pandey, V., Pawar, K., Verma, T., Jain, S., \& Mane, M. M.).

According to a survey, there are 250 million visually challenged people around the world. Such people need to have a third party to access their accounts and compose, send and read mails for them. However, this violates the security terms of the blind (Ingle, P., Kanade, H., \& Lanke, A. 2016).

For this purpose, we are developing a system Blind Mail that helps the blind person to access their e-mail accounts with their voice commands without being dependent on the third party. The blind person will be able to compose and access mails, as well as perform other useful tasks via his voice. The user of this system does not need to remember the keyboard shortcut and where the keys are located and the mouse clicks.

The rest of the paper is organized in different sections. Section 1 represents the Literature Review. In Section 2, we detailed the Problem Statement. Section 3 represents the Proposed Solution. Section 4 highlights the Design phase. Section 5 represents Implementation. Section 6 describes Goals and Objectives of the System. In Section 7, we have defined the Scope of Project. Section 8 represents the conclusion.

\section{Literature Review}

Existing systems that are available for blind people use simple speech to text and text to speech recognition. Keyboard shortcuts and mouse clicks are used in these systems, which is difficult to remember for a blind person (Shabana, T., Anam, A., Rafiya, A., \& Aisha, K. 2015), (Suresh, A., Paulose, B., Jagan, R., \& George, J. 2016).

Screen readers are used to read the content on the screen in existing systems, a person will have to use keyboard shortcuts to perform actions. It will be difficult for a blind person to remember and use keyboard shortcuts (Khan, R., Sharma, P. K., Raj, S., Verma, S. K., \& Katiyar, S). For this purpose, we have visited an institute for blinds 
where we have gathered their requirements about what more facilities, they want in an e-mail system. They highly emphasized on the use of totally voice based system without having to move the cursor thoroughly on the icons, as it takes a lot of time for a specific icon to be accessed (Ingle, P., Kanade, H., \& Lanke, A. 2016).

There are many systems available now a days but there is no proper system developed for the blind people yet, to aid them to use their e-mail accounts without being bounded as these systems used mouse interactions, keyboard shortcuts and IVR (Interactive Voice Response). IVR is a cutting edge innovation that depicts the intercommunication between the user and the system in the way of responding by using keyboard for the particular voice message. IVR permit users to connect and collaborate with an e-mail host system via a system keyboard, after that users can easily service their own enquiries by listening to the IVR dialogue (Ingle, P., Kanade, H., \& Lanke, A. 2016).

We visited a Blind School named "AKAB COMPLEX". We found out that they were using a desktop application "JAWS" that has a voice over specifying the particular icon to which a cursor is moved upon, using mouse. They access their E-mail accounts using this application, but there were some children who were not able to operate it, they found it hard to work on traditional keyboards as they forget the sequence of keys. Moreover, the major problem was as JAWS helps to access whatever we want to access by generating the voice pronouncing the name of icon when the cursor moves over the icon, but it takes a lot of time to access the targeted content. Since a blind person is unable to figure out where actually his desired icon or application lies. So, he has to go through many options coming in between the way to his desired option. Therefore, for this purpose we are building Blind E-mail System that does not require any of key operations. It is totally voice based and it utilizes WEB SPEECH API. In the Inbox page, after the right click user will be told about how many mails are there at the moment. For example, in case a user has 10 mails. If user says 5 , then the fifth mail will be opened and read out.

\section{Problem Statement}

Currently, there are many systems available, but there is no proper system developed for the blind people yet, to aid them to use their e-mail accounts without being bounded as these systems used mouse interactions and keyboard shortcuts (Nilesh, J., Alai, P., Swapnil, C., \& MR, B. 2014) (RAHMAN, D. M. M). As we have mentioned above that we have visited an institute for blind (AKAB COMPLEX). They were using the software named JAWS that utilizes the use of mouse clicks, but the visually impaired people find it very time consuming as they reach the desired icon after going through many icons coming on the way. They have to move the cursor throughout the screen to access their desired application or icon.

\section{Proposed Solution}

The most important thing kept in mind while developing the website is accessibility not only for abled but also for disabled people. Our website focuses on the friendliness of all the people including normal people, blind people as well as illiterate people (Sawant, S., Wani, A., Sagar, S., Vanjari, R., \& Dhage, M. R. 2018).

The website is based on IVR (Interactive Voice Response). The user will not require the use of keyboard and mouse clicks (just a single click anywhere on screen), they will provide the information through his voice that will be converted from speech to text and the content will be read out loud by system using text to speech. We are utilizing "Web Speech API" where both its functions "Speech Synthesis" and "Speech Recognition" are being implemented. Before utilizing Web Speech API, we jumped into using Google Speech API as it has more accuracy in showing the results but the drawback was the voice input was first sent to server and then server sends back the response. Therefore, it implies delay in presenting with the results due to Request and Response cycle of Google Speech API. While Web Speech API is faster and efficient in a way that it does not need to send the voice data on Internet for processing, it just does it instantly inside the browser API.

\subsection{Web Speech API}

The Web Speech API when embedded to a website enables it to provide the functionality of text-to-speech and speech-to-text.

\subsubsection{Speech Synthesis}

Speech synthesis is the process of making the system talk in artificially generated voice. The process of generating of spoken language by machine on the basis of written input.

\subsubsection{Speech Recognition}

Speech recognition is one of the versatile fields of computer science which provides the functionality of speech recognition and translates the spoken words or phrases into text. 


\section{Design}

\subsection{User Interface Design}

The user interface is design using Bootstrap and CSS. The focus was on the efficiency of the system as it is being developed for visionless people instead of the design of the interface. Therefore, the website has very simple interface (Khan, R., Sharma, P. K., Raj, S., Verma, S. K., \& Katiyar, S.), (Hari Priya, S. L., Karthigasree, S., \& Revathi, K. 2015).

\subsection{Database Design}

The database is being utilized for storing mails and maintaining user's privacy by storing user provided credentials. Therefore, no one except for the authentic and registered users, can access their private accounts. We have two tables stored in database that are a user table and an e-mail table (Khan, R., Sharma, P. K., Raj, S., Verma, S. K., \& Katiyar, S.) (Hari Priya, S. L., Karthigasree, S., \& Revathi, K. 2015).

\subsection{System Design}

The system is totally voice based. It works in a manner that it recognizes the speech input and convert it into text output and when the text is generated, it is read by the system to help the blind to know what he has written or what the system has understood with the help of speech synthesis. Figure1 represents the Data Flow Diagram that will help to illustrate the flow of the system (Khan, R., Sharma, P. K., Raj, S., Verma, S. K., \& Katiyar, S.).

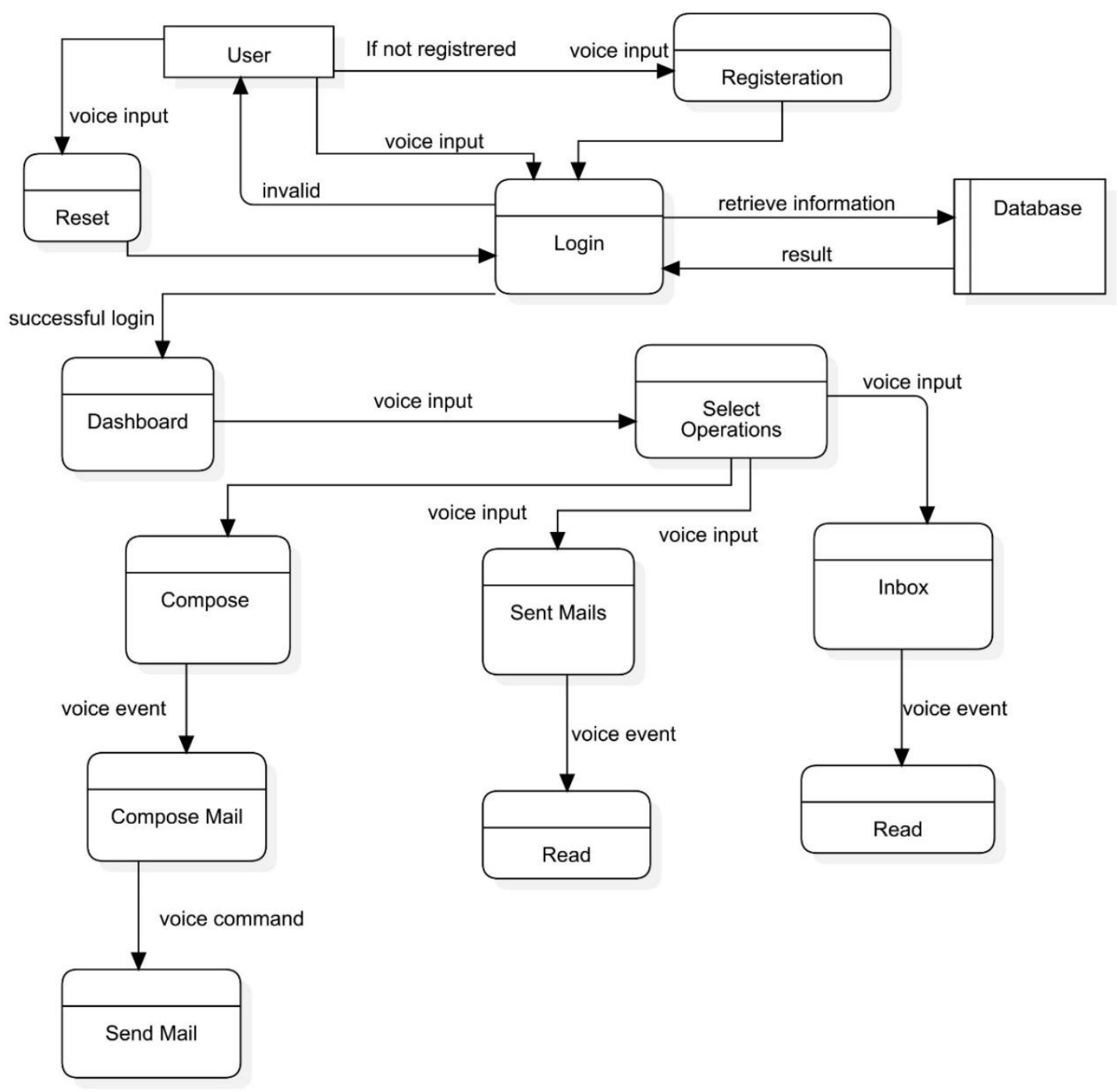

Figure 1. Data Flow Diagram of the System 


\subsection{Activity Diagrams}

In the following we represent the various Activity Diagrams of: Login, Registration, Reset, Compose Mail and the activity diagram of the Blind Electronic Mail System.

5.4.1 Login

The Figure 2 represents the activity diagram of Login.

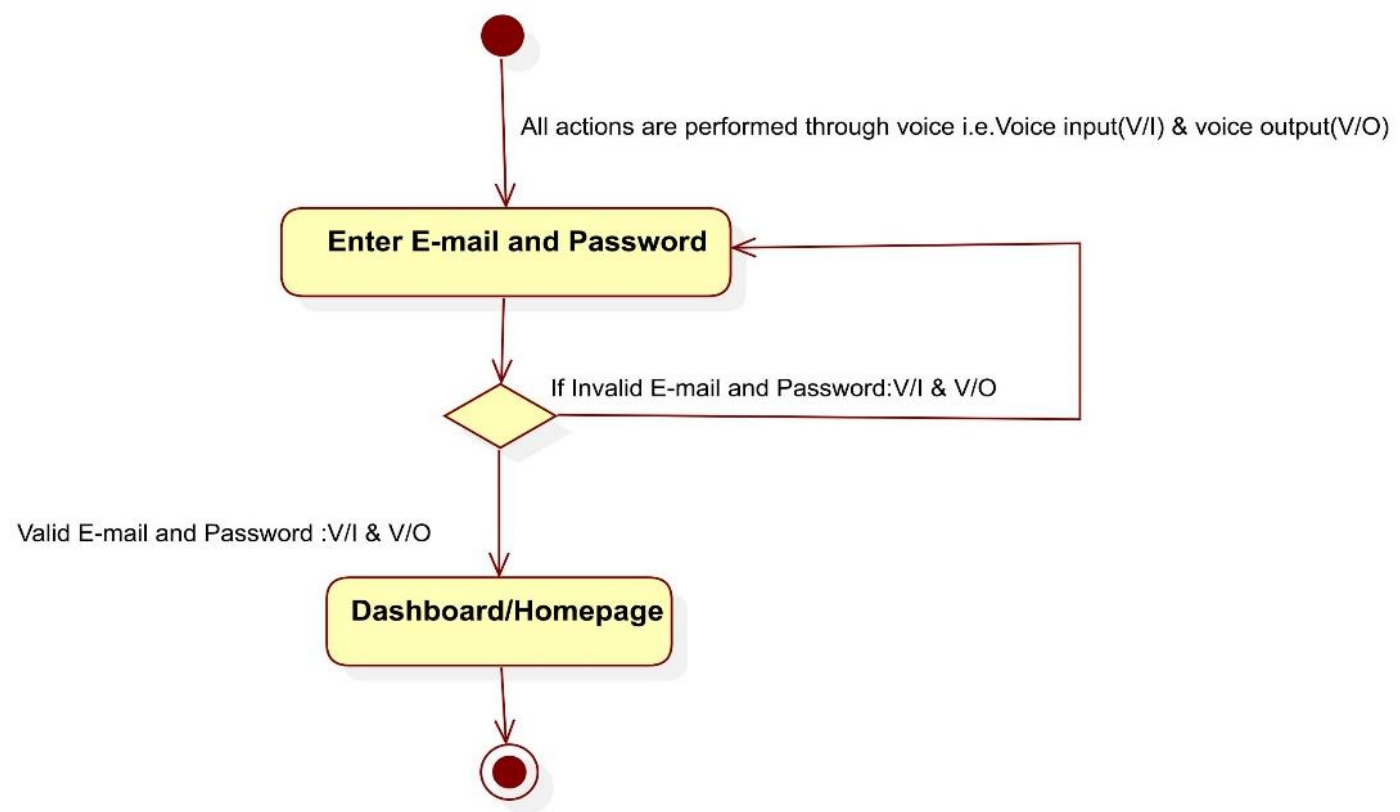

Figure 2. Activity diagram of Login

\subsubsection{Registration}

In Figure 3, we represent the activity diagram of Registration.

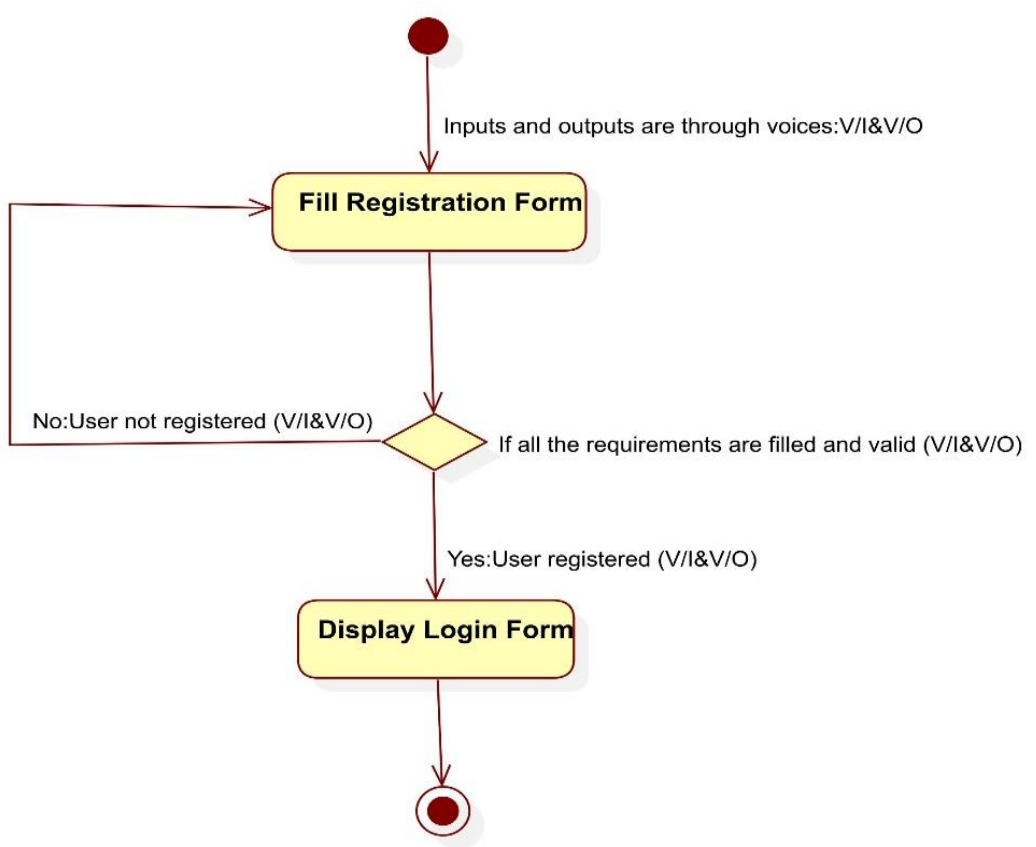

Figure 3. Activity diagram of Registration 


\subsubsection{Reset}

The Figure 4 represents the activity diagram of Reset.

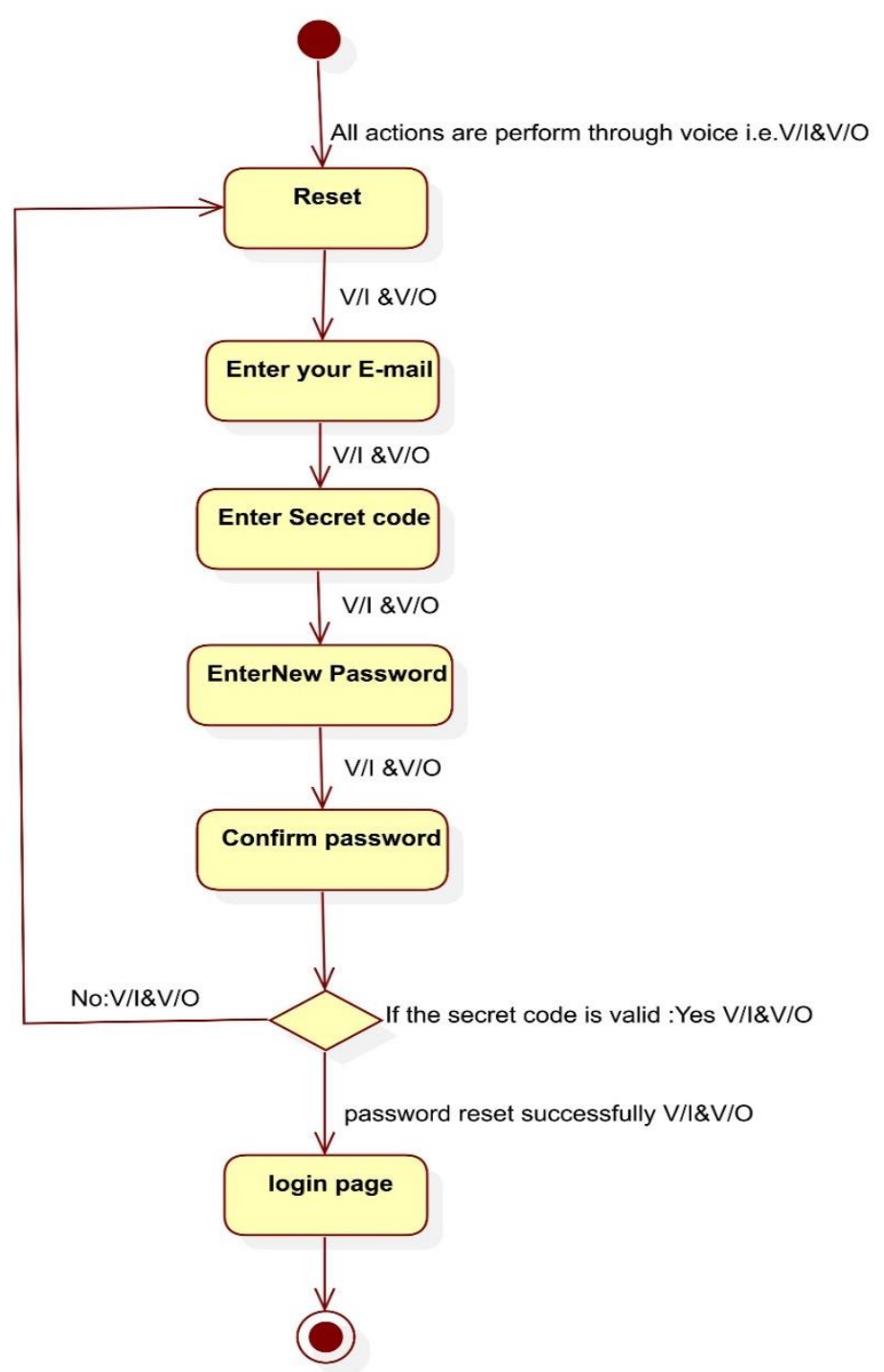

Figure 4. Activity diagram of Reset

\subsubsection{Compose Mail}

The Figure 5 represents the activity diagram of Compose Mail. 


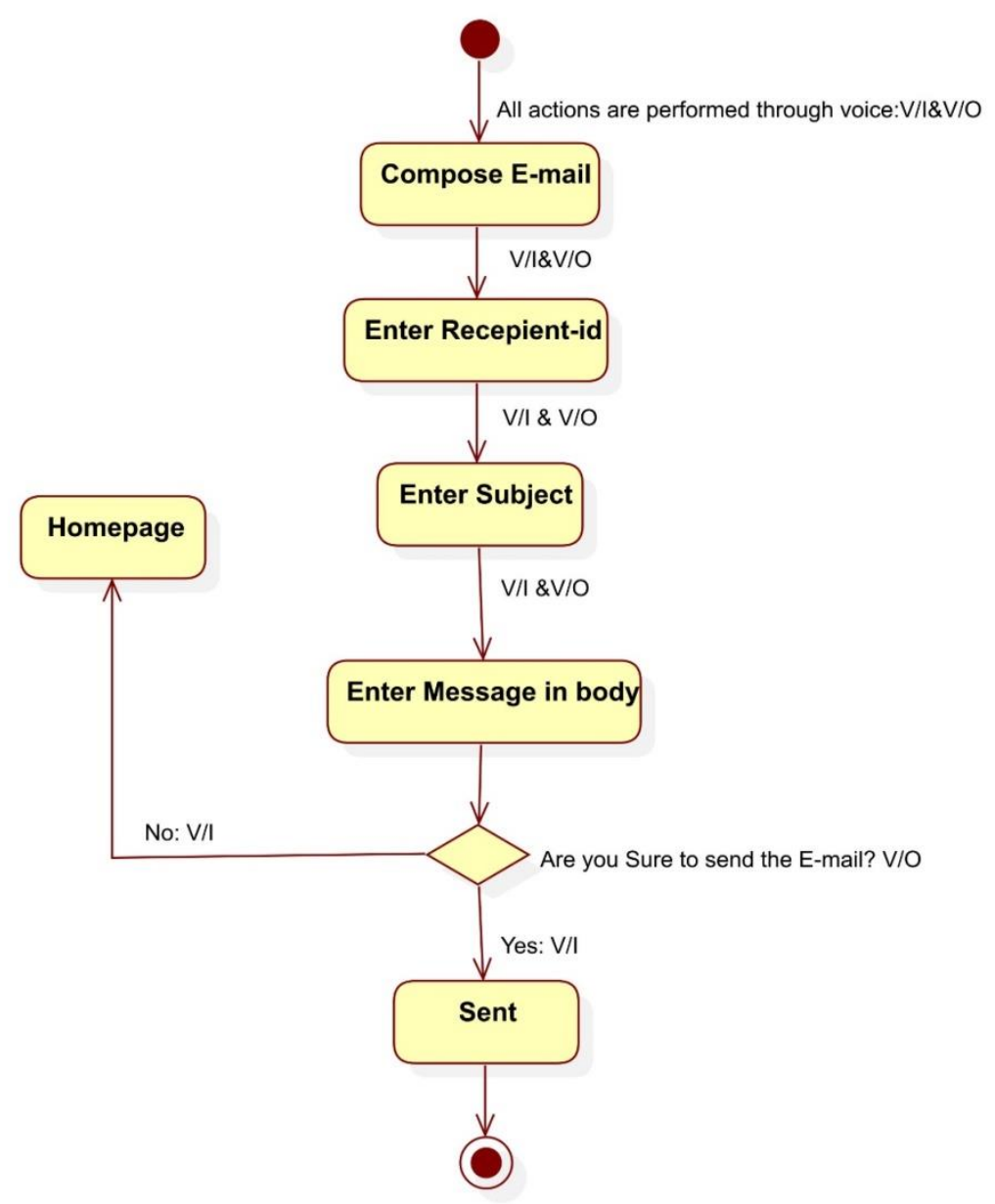

Figure 5. Activity diagram of Compose Mail

5.4.5 Activity Diagram of The Blind Electronic Mail System

In Figure 6, we represent the activity diagram of the Blind Electronic Mail System. 


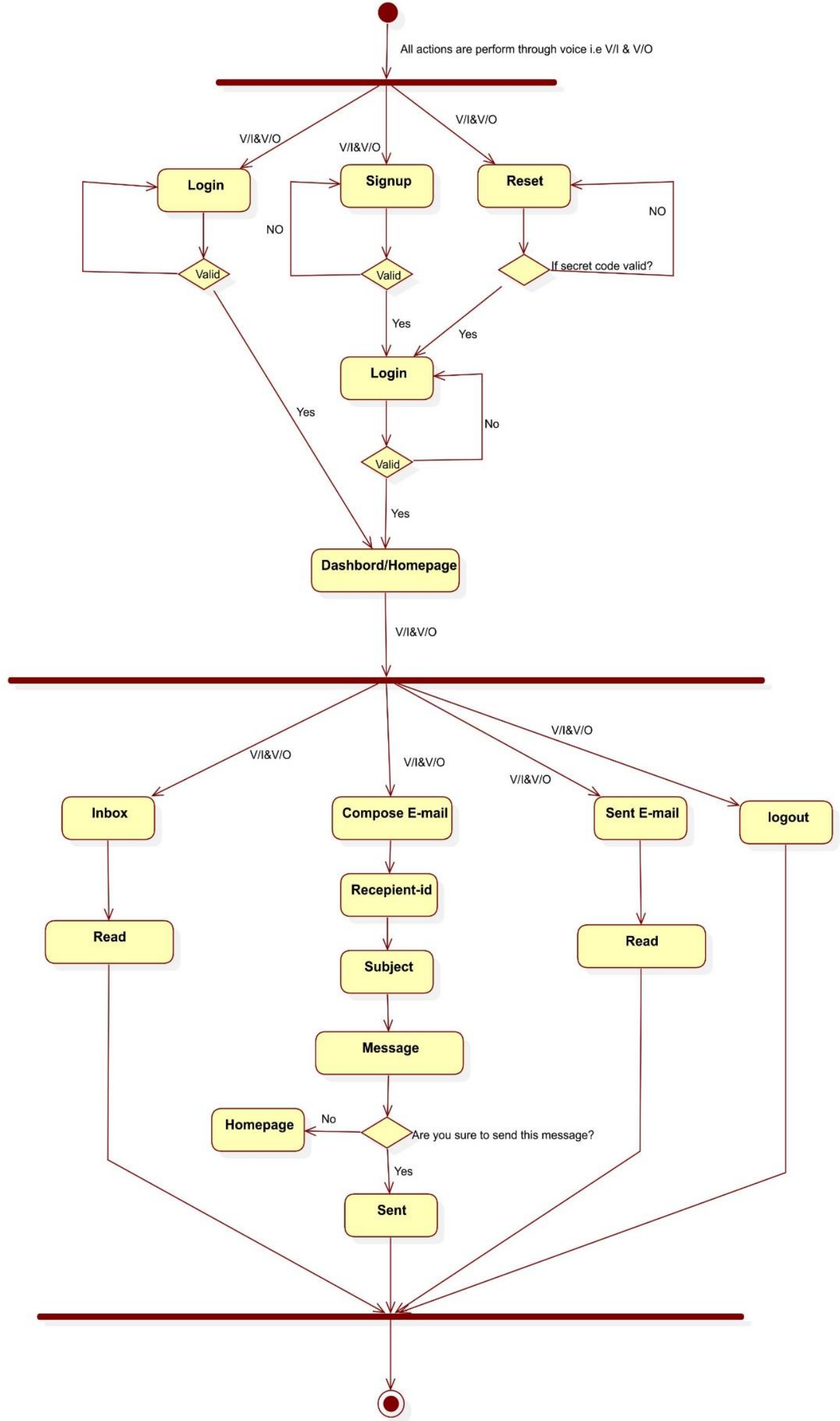

Figure 6. Activity diagram of the Blind Electronic Mail System 


\section{Implementation}

\subsection{Index Page}

Figure 7 represents the main page of the website. After the right click user will be given with three options that are Login, Sign up and Reset. The user will select the desired ones through his voice.
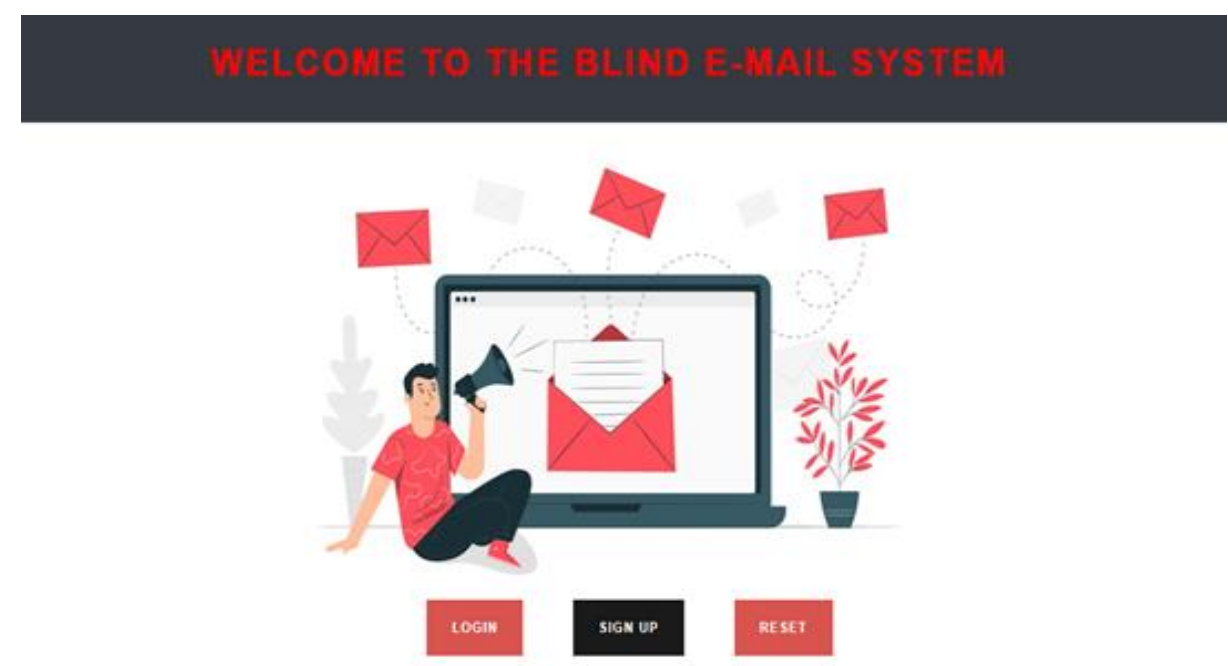

Figure 7. Main Page of the Blind E-mail System

\subsection{Registration}

To use the system the users will first have to register themselves. This module will gather all the information required to authenticate the users, as shown in Figure 8. The user will speak up the details, which will be converted to speech-to-text. If the information is valid, the user will be registered and the information will be stored in the database. If the information is invalid, the user will be asked to refill the registration form again through his voice.

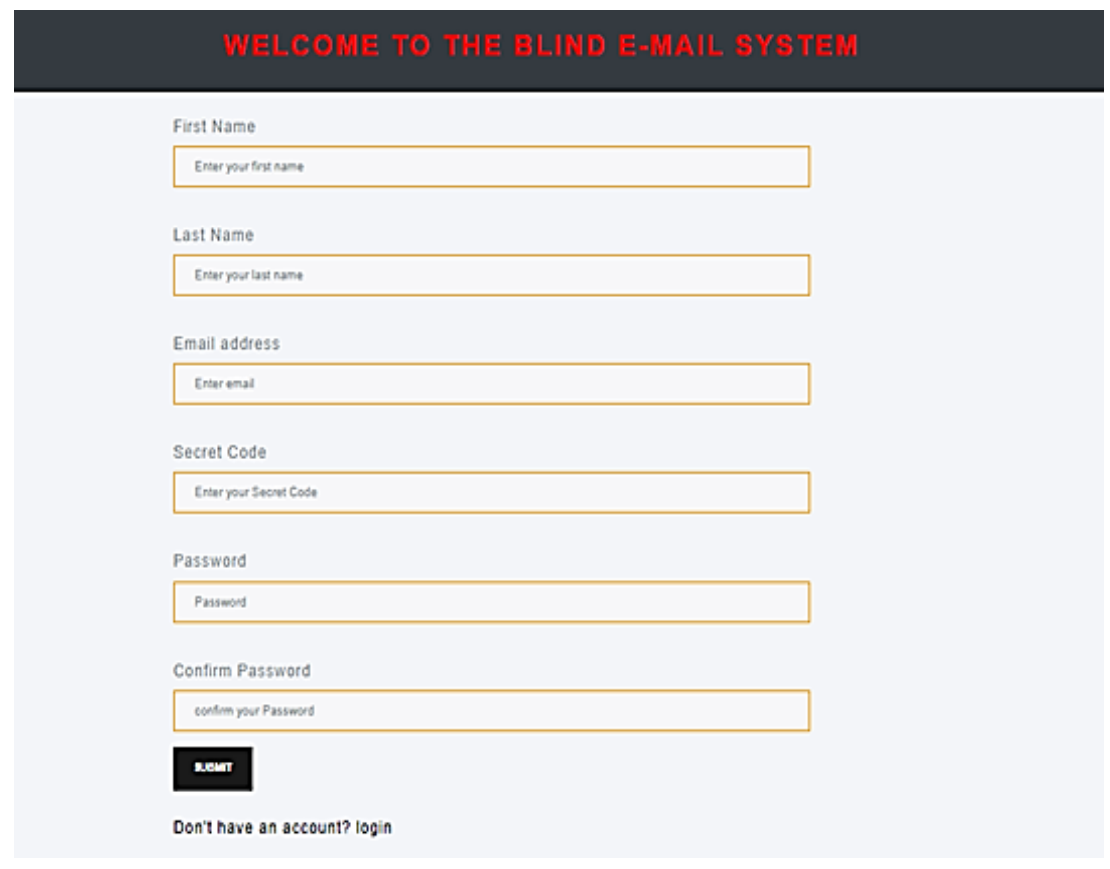

Figure 8. Registration Page of the Blind E-mail System 


\subsection{Login}

After the registration, now the user will be able to login. This module will ask the user to enter the username and password via speech, as shown in Figure 9. If the information is correctly entered, the system will direct the user to the home page.

\section{WELGOME TO THE BLIND E-MAIL SYSTEM}

Email address

Enter email

Password

Password

\section{LOGIN RESEI}

Don't have an account? signup here

Figure 9. Login Page of the Blind E-mail System

\subsection{Home Page}

In the home page (Figure 10) the user will be able to access inbox, compose and sent mails by his voice.

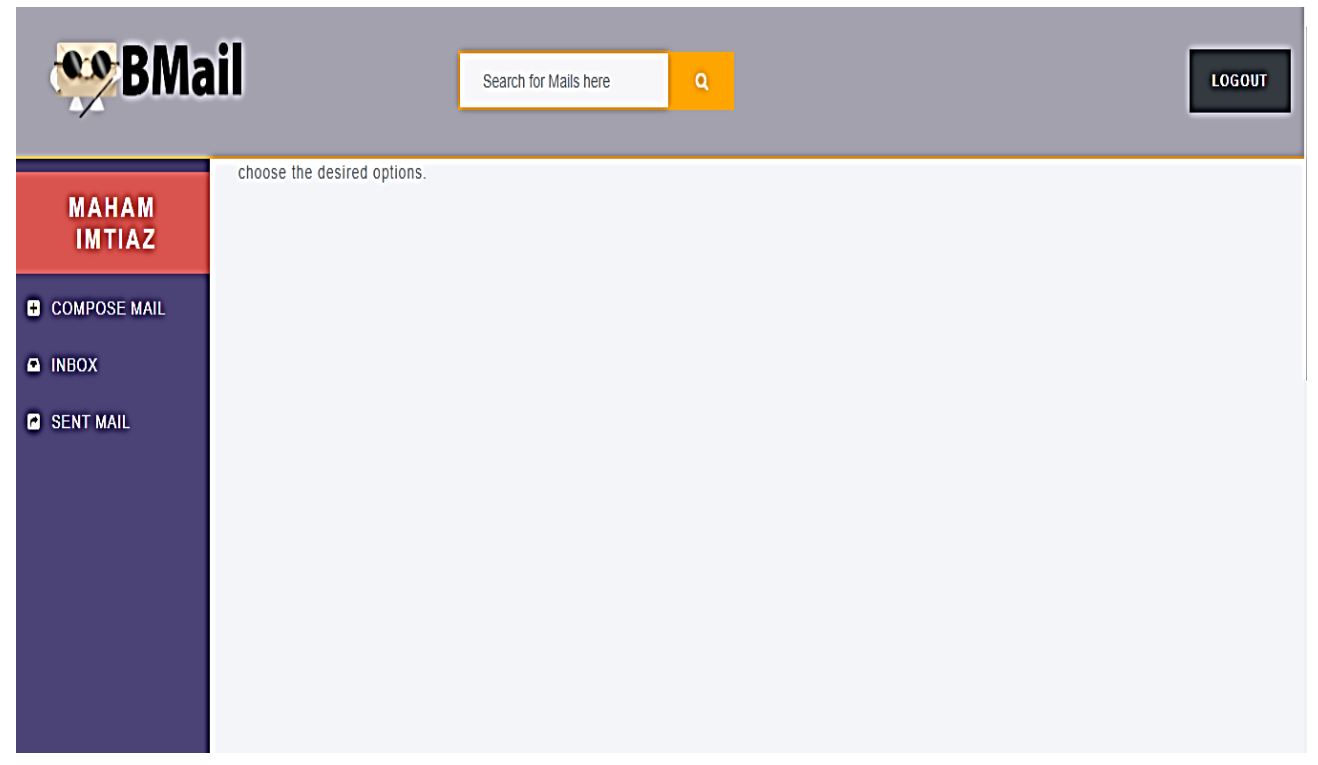

Figure 10. Home Page of the Blind E-mail System

\subsection{Compose Mail}

The user will be able to compose the message through voice commands, which will be at the instance, converted to text as the user speaks (Figure 11). And then, the text will be read out by computer interactive voice using speech synthesis. 


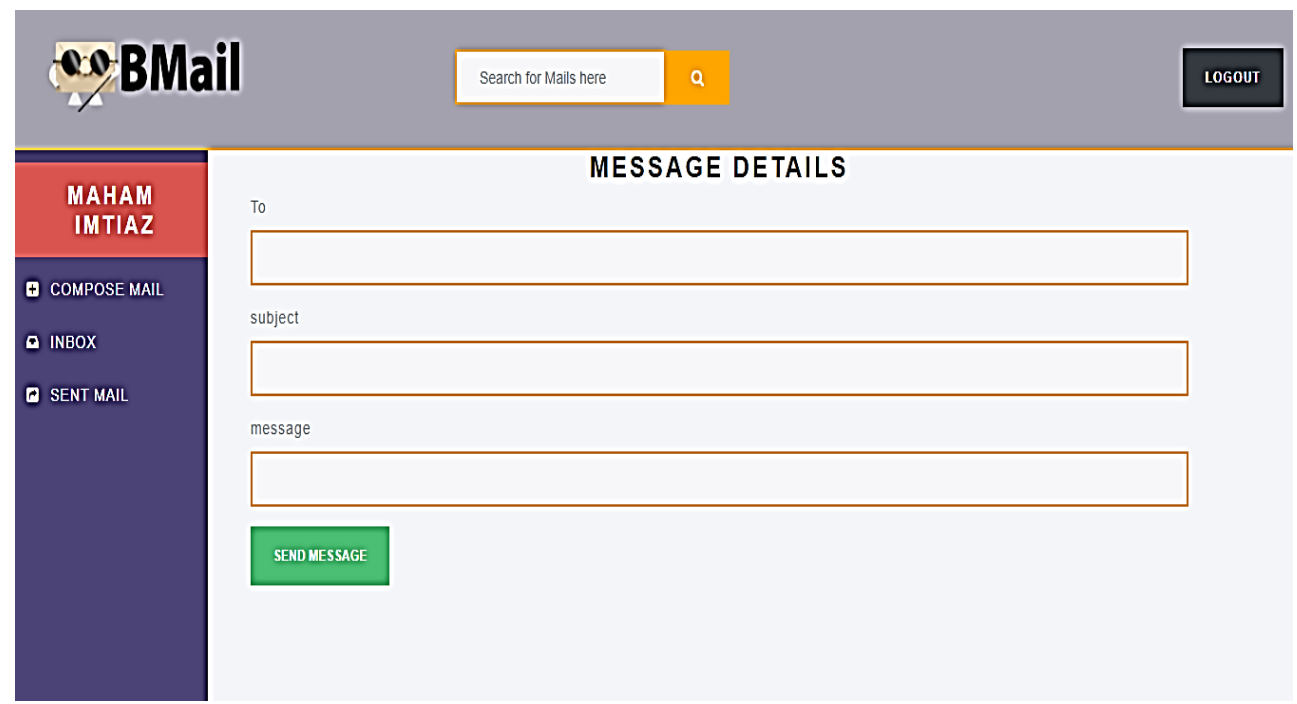

Figure 11. Compose Mail Page of the Blind E-mail System

\subsection{Inbox}

This module provides the user with the feature to access the inbox by saying inbox, as shown in Figure 12. It contains all the messages he has received. And, the desired mail will be read out by just saying the index number. In the Inbox page, after the right click user will be told about how many mails are there at the moment. For example, in case a user has 10 mails, if he says 5 , then the fifth mail will be opened and read out.

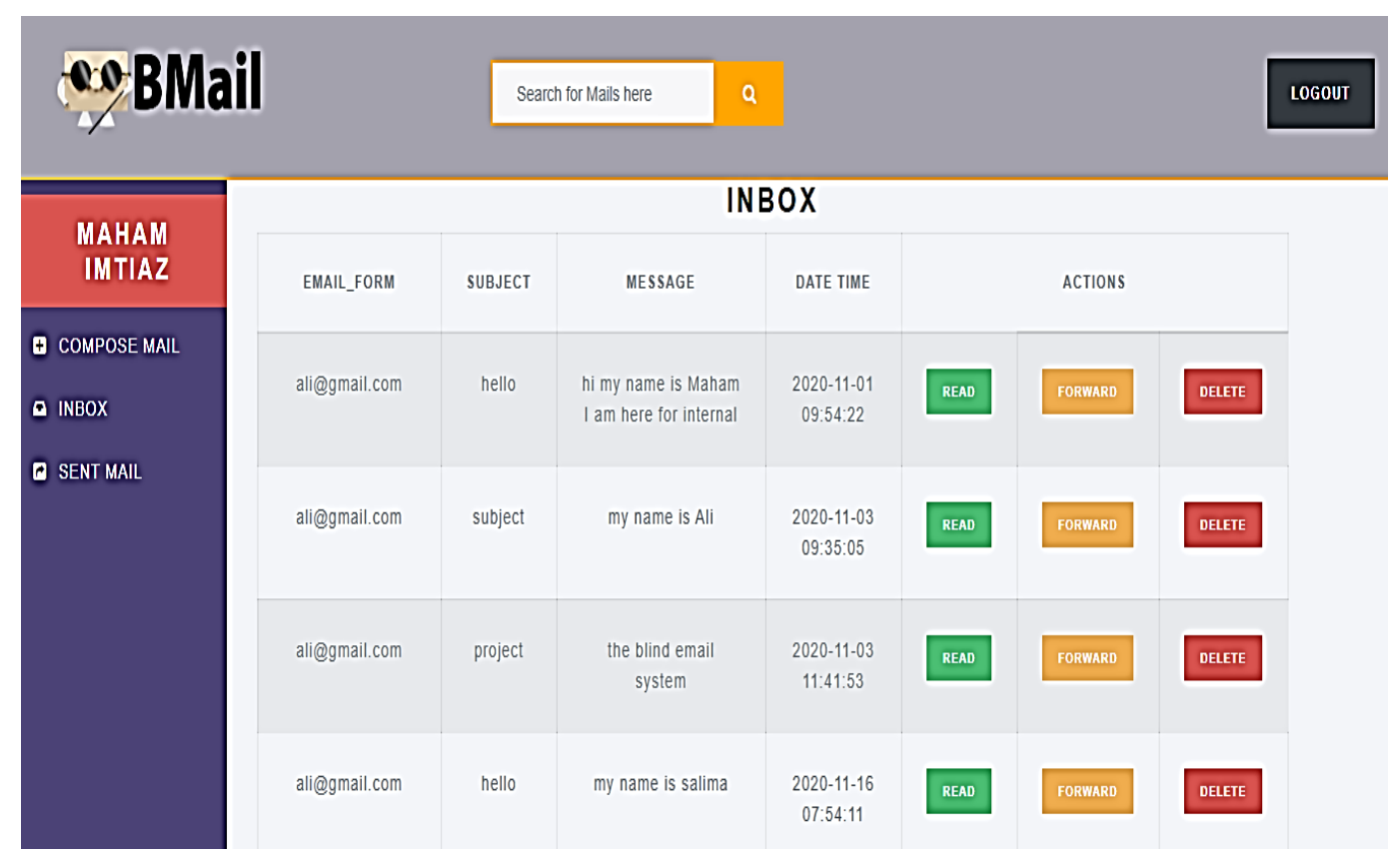

Figure 12. Inbox Page of the Blind E-mail System

\subsection{Sent Mail}

This module will keep the record of all the mails sent by the user. Mails will be read out through voice over when the user selects any mail by saying the index number, as shown in Figure 13. In the Sent Mail page, after the right click user will be told about how many mails are there at the moment. For example, a user has 10 mails, if he says 5 , then the fifth mail will be opened and read out. 


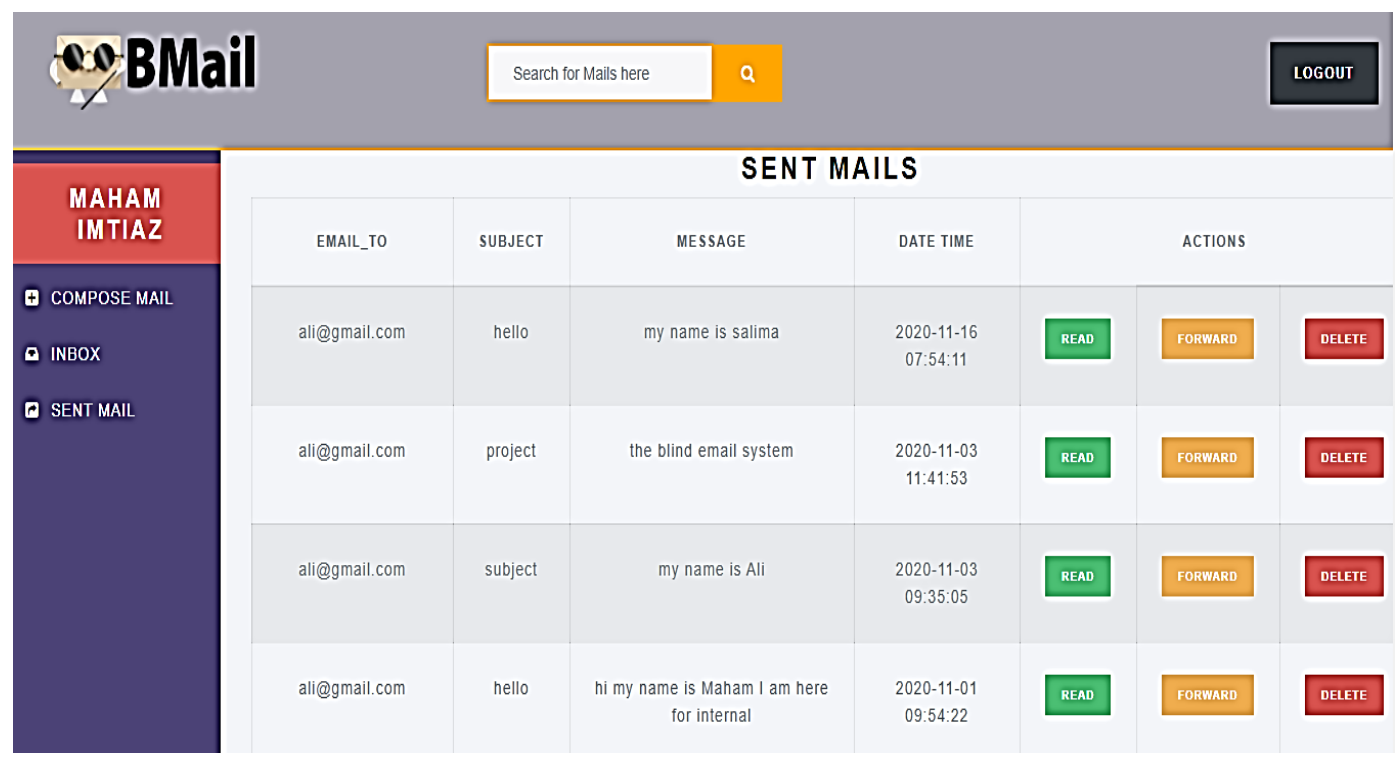

Figure 13. Sent Mail Page of the Blind E-mail System

\subsection{Reset Password}

This module will allow the user to reset his password by entering the secret code (whether in the form of pin or keywords), as shown in Figure 14. The user was asked to fill during registration of his account. The user will have to remember the secret code, otherwise he will lose his account.

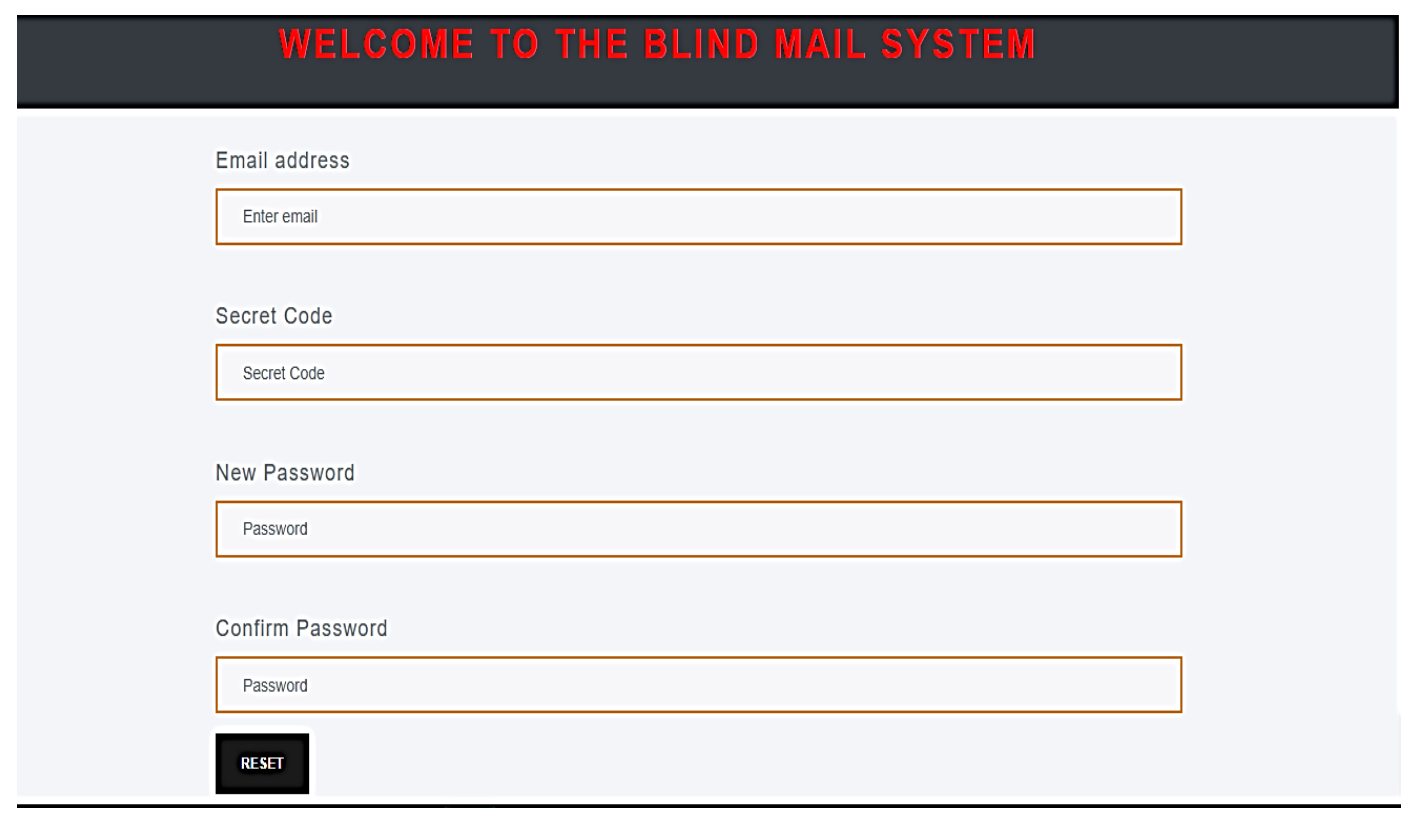

Figure 14. Reset Page of the Blind E-mail System

\section{Goals and Objectives}

The system is proposed to enable the visually impaired people to access their e-mail accounts through their voice. There is no need to use keyboard and mouse to interact with the system (mouse is utilized just for single right click on every page), all the operations will be performed with user voice. The users simply login to their system through their voice and are able to compose, read (read by the computer whatever transcript is given) and send mails. 


\section{Scope of the Project}

For the visually impaired people, it is a big deal to access the common e-mail systems. Therefore, the proposed system will be of great application for the visually impaired people as the system is designed with text-to-speech and speech-to-text that enables them to access their account, compose and send mails without having to be restricted to keyboard (Jayachandran, K., \& Anbumani, P. 2017).

\section{Conclusion}

The major purpose of developing this system is to help the visually challenged people to access the most popular mode of communication that is E-mail. The visionless people will be able to interact with the system using their voice and that system in return will convert the voice into text and that computer-generated voice will help the blinds to direct them on which page they are now and what should they do further. In this way, this system would be of great use for the visually impaired people.

\section{References}

Hari Priya, S. L., Karthigasree, S., \& Revathi, K. (2015). Voice-Based E-Mail (V-Mail) for blind. International Journal.Retrieved from https://www.academia.edu/15414771/Voice_Based_E_Mail_V_Mail_for_blind

Ingle, P., Kanade, H., \& Lanke, A. (2016). Voice based e-mail System for Blinds. International Journal of Research Studies in Computer Science and Engineering (IJRSCSE), 25-30. https://doi.org/10.20431/2349-4859.0301005

Jayachandran, K., \& Anbumani, P. (2017). Voice based email for blind people. Int. J. Adv. Res. Ideas Innov. Technol., 3(3), 1065-1071. Retrieved from https://www.ijariit.com/manuscripts/v3i3/V3I3-1462.pdf

Khan, R., Sharma, P. K., Raj, S., Verma, S. K., \& Katiyar, S. (2020). Voice Based E-Mail System using Artficial Intelligence. Retrieved from

https://www.researchgate.net/publication/341001786_Voice_Based_E-Mail_System_using_Artificial_Intelli gence

Latha, L., Babu, B., \& Sowndharya, S. (2020). VOICE BASED EMAIL WITH SECURITY FOR VISUALLY CHALLENGED. Retrieved from https://www.ijeat.org/wp-content/uploads/papers/v8i6S3/F12060986S319.pdf

Nilesh, J., Alai, P., Swapnil, C., \& MR, B. (2014). Voice based System in Desktop and Mobile devices for blind people. International Journal of Emerging Technology and Advanced Engineering (IJETAE), 4(2), 404-407. Retrieved from http://citeseerx.ist.psu.edu/viewdoc/summary?doi=10.1.1.638.762

Pandey, V., Pawar, K., Verma, T., Jain, S., \& Mane, M. M. (2020). Voiced Based E-mail System. https://doi.org/10.29322/IJSRP.9.03.2019.p8797

Sawant, S., Wani, A., Sagar, S., Vanjari, R., \& Dhage, M. R. (2018). Speech Based E-mail System for Blind and Illiterate People. International Research Journal of Engineering and Technology (IRJET) e-ISSN, 2395-0056. Retrieved from https://www.irjet.net/archives/V5/i4/IRJET-V5I4532.pdf

Shabana, T., Anam, A., Rafiya, A., \& Aisha, K. (2015). Voice based email system for blinds. International Journal of Advance Foundation And Research In Science \& Engineering (IJAFRSE), 1. https://doi.org/10.17148/IJARCCE.2015.4163

Suresh, A., Paulose, B., Jagan, R., \& George, J. (2016). Voice Based Email for Blind. Retrieved from https://www.academia.edu/26662847/Voice_Based_Email_for_Blind

\section{Copyrights}

Copyright for this article is retained by the author(s), with first publication rights granted to the journal.

This is an open-access article distributed under the terms and conditions of the Creative Commons Attribution license (http://creativecommons.org/licenses/by/4.0/). 